\title{
Regulatory Influence of Procambarusclarkii, Girad (Decapoda: Cambaridae) On Schistosome-Transmitting Snails in Lotic Habitats within the River Athi Basin, Kenya
}

\author{
Maina GM ${ }^{1,3^{*}}$, Kinuthia JM${ }^{1}$, Mutuku MW ${ }^{1}$, Mwangi $\mathrm{IN}^{1}$, Agola $\mathrm{EL}^{1}$, Kutima $\mathrm{HL}^{2}$ and \\ Mkoji GM ${ }^{1}$ \\ ${ }^{1}$ Centre for Biotechnology Research and Development, Kenya Medical Research Institute, Nairobi, Kenya \\ ${ }^{2}$ Department of Zoology, Jomo Kenyatta University College of Agriculture and Technology, Juja, Kenya \\ ${ }^{3}$ College of Health Sciences, Institute of Tropical Medicine and Infectious Diseases (ITROMID), Jomo \\ Kenyatta University of Agriculture and Technology, Juja, Kenya
}

Received: September 21, 2017; Accepted: October 05, 2017; Published: October 11, 2017

*Corresponding author: Maina GM, Centre for Biotechnology Research and Development, Kenya Medical Research Institute, Nairobi, Kenya, Tel: +254720999 586; E-mail: gmaina@kemri.org

\begin{abstract}
Background \& Objective: Control of schistosomiasis, a neglected tropical disease has for a long time overly relied on praziquantel. Crayfish, though voracious snail eaters have been tested in small man-made impoundments but not in lotic habitats. The present study aimed to determine the ability of the crayfish, Procambarus clarkii to reduce populations of schistosome transmitting snails in lotic habitats.

Methods: Data was collected bi-monthly on the presence or absence of snails and crayfish in 4 stream habitats, over a period of 10 months, and these were identified from a baseline survey to be habitats for Biomphalaria snails, transmitters of intestinal schistosomiasis, and were located in the Machakos County within the Athi River basin in south-eastern Kenya. Subsequently, 2 of the habitats were selected for introduction of crayfish (and were designated "experimental sites") and the other 2 habitats were designated "control sites." Each of the "experimental sites" received 110 crayfish. The study sites were sampled for snails using standard snail scoops and for crayfish using meat-baited crayfish traps. The bi-monthly sampling of the habitats was done to determine snail abundance, crayfish survival, and obtain information on biotic and abiotic parameters.
\end{abstract}

Results: Snail abundance in the habitats that received crayfish rapidly declined within 2 months to a significant level compared with the initial abundance (paired t test $=5.524, p$ value $=0.0001$ ), relative to the decline observed in the control habitats (paired test $=7.727, p$ value $=0.082$ ).

Interpretation \& Conclusion: While P. clarkii holds much promise as a complimentary schistosomiasis control strategy to chemotherapy, restocking of habitats should be considered when habitats dry up during extreme weather conditions, for effectiveness of this approach.

Keywords: Crayfish; Predation; Planorbid snails; Biomphalaria pfeifferi; Seasonal streams; Schistosoma mansoni

\section{Introduction}

Schistosomiasis is one of the several so-called neglected tropical diseases (NTDs) that are pervasive in sub-Saharan Africa and elsewhere in the developing world [1]. Various strategies for control include chemotherapy to treat infected people, improved sanitation, public health education programs, and snail control [2]. Today, public health campaigns in endemic regions focus on mass drug administration using the oral drug, praziquantel (PZQ) [3]. Although PZQ is fairly efficacious against the sexually mature forms of the parasite, it is often unable to kill juvenile schistosomes present in the human body [4]. Additionally, there is concern that with the intensive use of PZQ drug resistance could render PZQ ineffective; given that drug resistant strains can easily be selected in the laboratory [5] and field derived strains with reduced susceptibility have been described [6]. Although artemether is known to be effective against immature schistosomes in the definitive host6and since most of the schistosomiasis endemic areas are also endemic for malaria transmission, there is reluctance to use it in such areas for fear of emergence artemether resistance [7]. Efforts to control the snail populations in the past through the use of chemicals or through alteration of snail habitats have resulted in environmental pollution and damage [8]. Another shortcoming associated with chemotherapy is that continued re-exposure to cercarial infested water leads to rapid re-infections of successfully treated patients in the endemic areas $[9,10,11]$.

Biological control of schistosomiasis as a complimentary strategy to existing control strategies is not commonly used in 
control programs primarily because it may involve use of exotic species which may negatively impact the local environment, possibly leading to extinction of the native bio-diversity [12]. However, studies carried out on fresh water snails in the Neotropical area have shown that the invading species may have a positive influence from the human health point of view, if their introduction leads to displacement of snail species that are responsible for the transmission of schistosomiasis [13]. The case of Martinique Island is especially relevant as a successful bio-control strategy where Biomphalaria glabrata and Biomphalaria straminea were displaced by the thiariid, Melanoides tuberculata after its accidental introduction into this island $[14,15]$. A bacterial pathogen of snails, Paenibacillus glabratella, has also, been tested on B. glabrata. The bacterium causes massive mortality and affects both the adult and neonate snails [16]. However, it is unclear at this point; if the bacterium is specifically infective to the snails that serve as intermediate hosts for schistosomes, or it can also, infect other invertebrate species. A river prawn,Macrobrachium vollenhovenii, has also, been tested with varying success in River Senegal, Diama Dam, using the male prawns [17].

The red swamp crayfish, Procambarus clarkii, $\alpha$ native of South-Central United States and North-Eastern Mexico, has been introduced to Europe, Africa, Central and South America and South-East Asia [18]. It was introduced into Lake Naivasha in Rift Valley, Kenya in the 1970's, and has since spread throughout several parts of Kenya. Previous studies indicated that P. Clarkiiis an effective predator of snails [20], rapidly eliminated snail populations in small man-made ponds [19], and, effectively reduced schistosomiasis transmission in such habitats [20]. However, no studies have been done in seasonal stream habitats which also, form significant foci for schistosomiasis transmission in endemic areas such as Kenya. In the present study, P. clarkii was tested for its ability to eliminate Biomphalaria pfeiferi, the freshwater snails involved in the transmission of $S$. mansoniin stream habitats located in the Machakos County, within the River Athi Basin.

\section{Materials and Methods}

\section{Study Approvals}

This study received approval from the Kenya Medical Research Institute (KEMRI) through its Scientific and Ethical Review Unit (SERU) and is referenced SSC No. 2798. Permission to undertake this study was also, obtained from the Kenya Wildlife Services (in a letter referenced KWS/BRM/5001) and the National Environment Management Authority (NEMA/10/22/VOL.1). The purpose of the study was explained to the local community in both the Kiswahili language and in the local Kikamba language, particularly to the people that lived near or frequently utilized the study habitats.

\section{Biosafety Matters}

Latex rubber gloves were worn by the project staff during snail sampling to prevent accidental exposure to schistosomecercariae, while heavy duty leather gloves were worn to prevent accidental crayfish bites during sampling.

\section{Study Area}

The study was undertaken in the Machakos County of Kenya, in localities within the River Athi Basin, in seasonal streams, identified through an initial survey as habitats for Biomphalaria pfeifferi, a prominent snail host of Schistosoma mansoni, the causal agent of intestinal schistosomiasis.

\section{Baseline Survey and Data Collection}

Out of the 15 stream habitats surveyed in the area, 4 were selected as the study habitats, and were sampled bi-monthly between June 2014 and March 2016. Two of the 4 selected study stream habitats (namely Kyanguli and KwaMutanga streams) were designated "Experimental" and received crayfish after an initial 6-months baseline sampling. The other 2 (Kyaana and Kamuongo) were designated as "Control" and no crayfish were introduced into the habitats. All the 4 study habitats selected had thriving populations of B. Pfeifferisnails which persisted for the 6 months all the habitats were sampled, prior to the introduction of crayfish into the "Experimental" sites. In each study habitat, 3 sampling stations were identified and marked, and were sampled during each visit to the habitats. The study habitats were sampled to determine presence or absence of crayfish, snail and crayfish abundance, and to determine schistosome infection prevalence in the snail populations.

\section{Snail Sampling and Screening}

Snails were sampled in all the 4 study habitats at designated sampling stations using standard snail scoops made of stainless steel sieves with a mesh size of $2 \times 2 \mathrm{~mm}$, supported on an iron frame, and mounted on a $1.5 \mathrm{~m}$ long wooden handle. Snails were sampled for $15 \mathrm{~min}$ at each sampling station along the littoral zones. Sampling was done between $0900 \mathrm{hrs}$ and $1230 \mathrm{hrs}$. The snails collected were sorted into species, counted, and screened for mammalian schistosome infections. Screening for schistosome infections was done using the "shedding" method in which the snails are isolated individually into wells of 24 -well culture plates in $1 \mathrm{ml}$ of mineral or aerated water, and left under natural or artificial light for $1.5-2 \mathrm{hr}$ to induce release of the schistosome larval forms known as cercariae, which develop in the snails and are infective to humans and other susceptible mammalian hosts.

\section{Crayfish Sampling}

Crayfish were sampled using locally made traps of plain wire and onion bags as shown in (Figure 1). The wire was cut into several $45 \mathrm{~cm}$ pieces. Where 3 pieces were folded to form circles and welded at the joints. Three straight wires were running the length of the three circles at equal distances and riveted at each point of contact with the circular wires. The traps were randomly placed in the water, and left for a maximum of $1 \mathrm{hr}$, but were checked at 15 min intervals. Any crayfish caught were removed from the traps and placed in a lidded plastic bucket. The captured crayfish were then sized, sexed, counted, and then returned into the water after sampling. Only male catches were analyzed because they provided the best index of crayfish abundance [21]. 


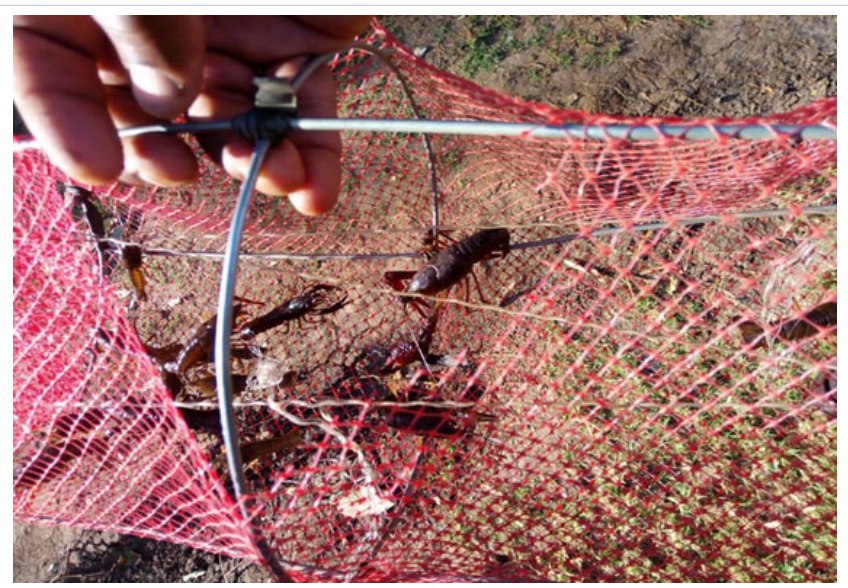

Figure 1: A photograph of trapped crayfish taken at Kyanguli stream (Experimental) where the crustaceans established thriving populations leading to decimation of snails.

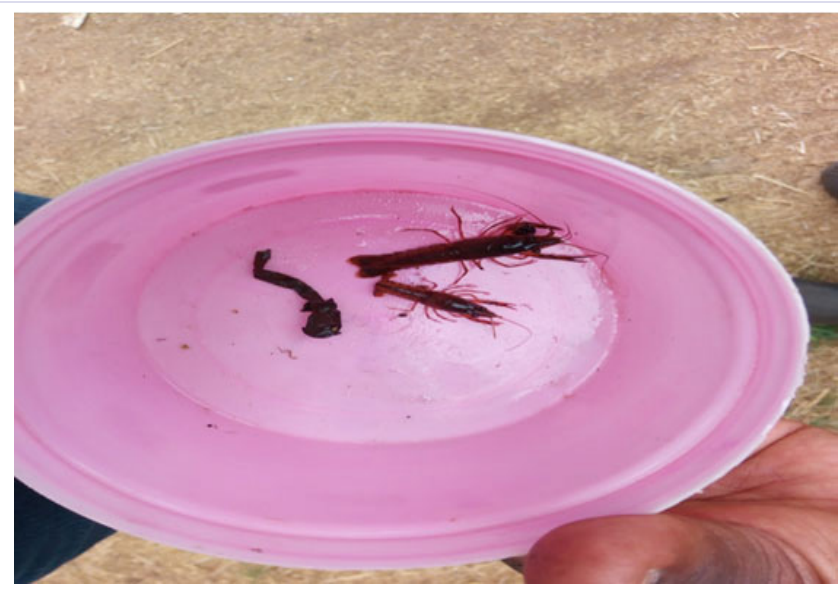

Figure 2: Juvenile crayfish

\section{Results}

\section{The Study Habitats}

The streams discharge is highly seasonal with peak flow in April-May when flooding is sometime observed and scanty flow in December-February. The streams bed is very variable ranging from rocky bed, large blocks $(>1 \mathrm{~m})$, stones $(5-25 \mathrm{~cm})$, coarse and fine gravel $(2-50 \mathrm{~mm})$, and sand $(<2 \mathrm{~mm})$ with fine organic matter in small pools. Both emergent and sub-mergent aquatic macrophytes occur. Most of the streams habitats are still kept in natural status save for sand harvesting and small scale irrigation. Anthropogenic activities in these streams include but not limited to; clothes washing, bathing, watering domestic animals, fetching water for domestic use, manual and mechanized small scale irrigation.

\section{Snail Species Present in the Study Habitats}

Several snail species inhabit the streams including B. pfeifferi, B. nasutus, B. forskalii, Ceratophalus and Lymnea natalensis. A total of 2325 schistosome transmitting snails (B. pfeifferi and B. nasutus) were sampled during the September 2014-March 2016 in the 4 study streams. The number of the other species sampled was small with $B$. forskalii at 17, Lymneanatalensis, 125 and Ceratophalusat 23.

\section{Crayfish Performance in the New Habitats}

Following crayfish introduction in Kyanguli and KwaMutanga streams, the crayfish were able to establish thriving populations at Kyanguli. During the 20 month period of the survey, 6 juvenile crayfish, an indication of breeding, were spotted on the edges of the experimental streams. 77 adult predators were captured in Kyanguli stream over the entire study duration while 28 adult crayfish in Kwamutanga within the first 3 months post introduction. (Figure 3) shows juvenile crayfish captured at Kyanguli stream.

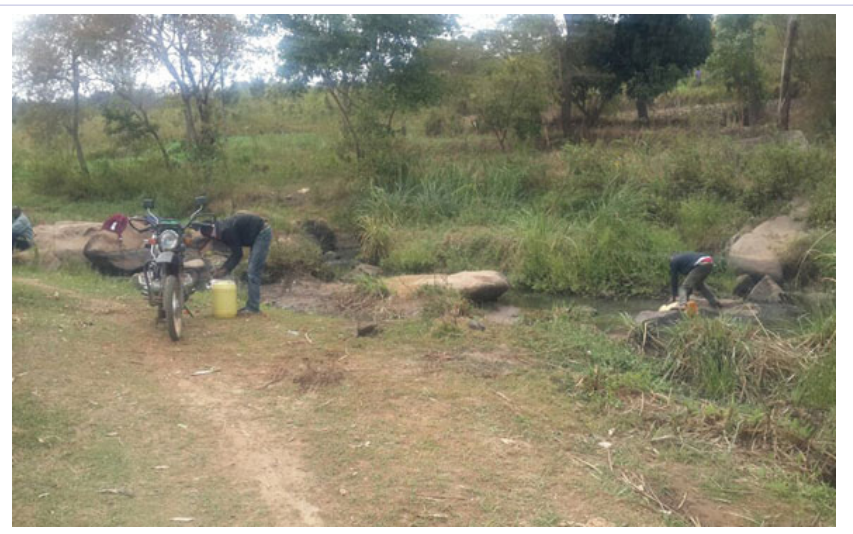

Figure 3: KwaMutanga stream, a motor cycle taxi (Bodaboda) washing site, and where crayfish failed to survive or establish a population, after introduction

\section{Snail Abundance in the Study Habitats}

After introduction of the crayfish in the "Experimental" habitats, a rapid decline in snail abundance was observed. For instance, within 3 months of crayfish introduction, snails completely disappeared at Kyanguli stream, never came back during the next 12 months of sampling at this habitat. At KwaMutanga stream, the snail abundance declined rapidly as well within 2 months of crayfish introduction (Figure 6). However, crayfish had rarely established at this site due to human activities specifically cleaning of motor bikes (Figure 3). On the other hand, snails remained relatively abundant in the "Control" habitats (Kyaana and Kamuongo streams), even though the numbers fluctuated over time, during the observation period, snails never completely disappeared from these habitats (Figure 7).

The population of snails sampled was more in experimental streams than in control stream. This could be attributed to the accuracy of the sampling method or even natural variation of the population density due to breeding or even habitat suitability. However, the population in control streams grew to almost same levels as in experimental streams by January 2015 just before crayfish was introduced. This provides a basis to evaluate the effect of crayfish on snail population density that would be used as potential biological control for schistosomiasis. 


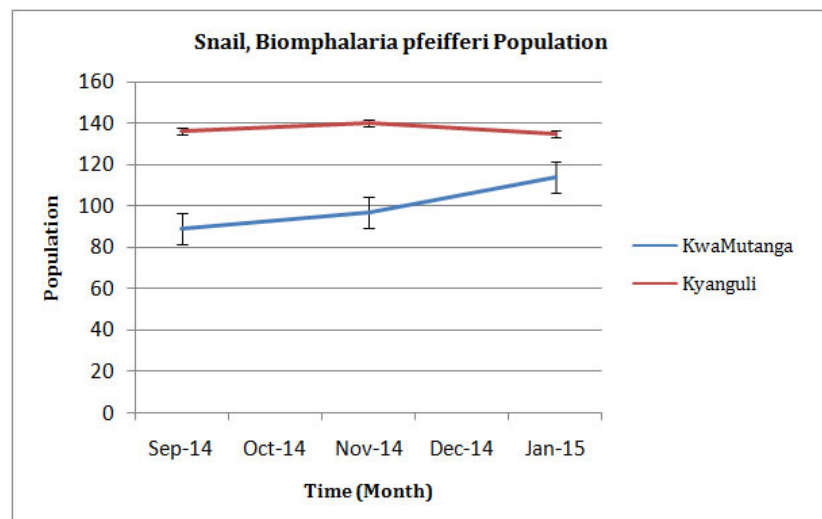

Figure 4: Snail abundance in experimental streams before Crayfish introduction

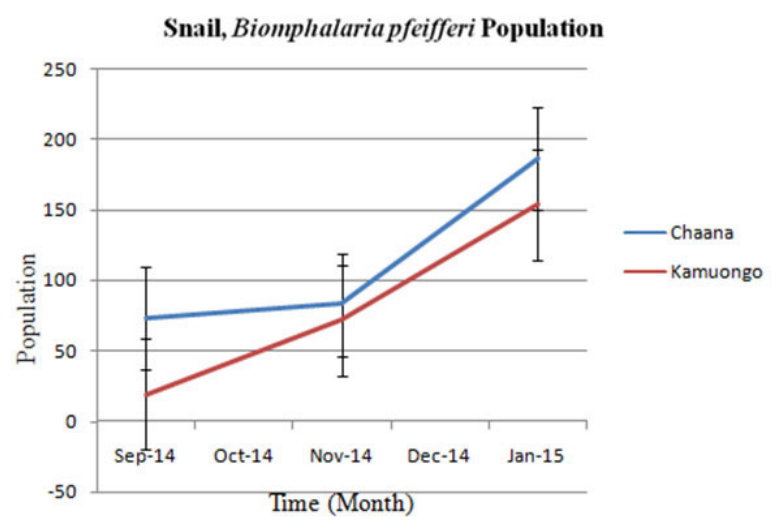

Figure 5: Snail abundance in Control streams before crayfish was introduced in experimental streams

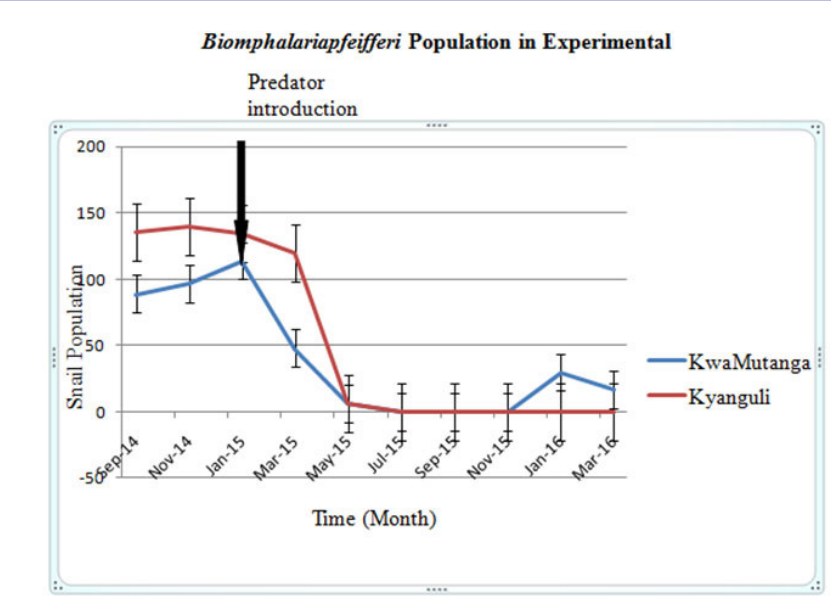

Figure 6: Snail abundance after crayfish introduction (Experimental)

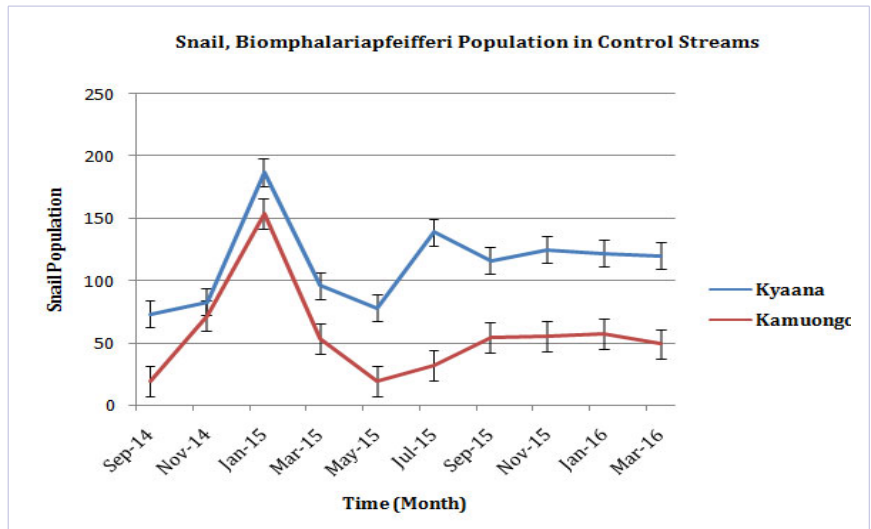

Figure 7: Snail abundance in control streams over the study period

The snail population in experimental streams was significantly reduced (paired $t$ test $=5.524, p$ value $=0.0001$ ) compared to control streams (paired $t$ test $=7.727, p$ value $=0.082$ ) after the crayfish was introduced. This indicates that the crayfish was able to establish in the habitat and feed on snail as one of their source if nutrients for survival.

\section{Comparison of Experimental and Control snail abundance after crayfish introduction}

Kwamutanga stream (Figure 8) the crayfish temporarily established within the first 3 months post introduction, almost wiped out the snails, but the crayfish pettered out by the 4 th month leading to a resurgent of snails, may be due to the stream being used for motorcycle taxi washing. However, in Kyaana stream (control) snail population declined from January 2015 till May due to drying of the river and then increased during the months of June and July 2015 (Figure 9). A slight decrease was observed during August as water levels declined and then a steady population reached from November 2015 through March 2016 in Kyaana stream. A comparison using one sample $t$ test showed a significant difference $(t=10.575, p=0.0001)$. This shows despite environmental changes such as flooding, drying and human activity, crayfish fed on snail leading to a significant drop in their population.

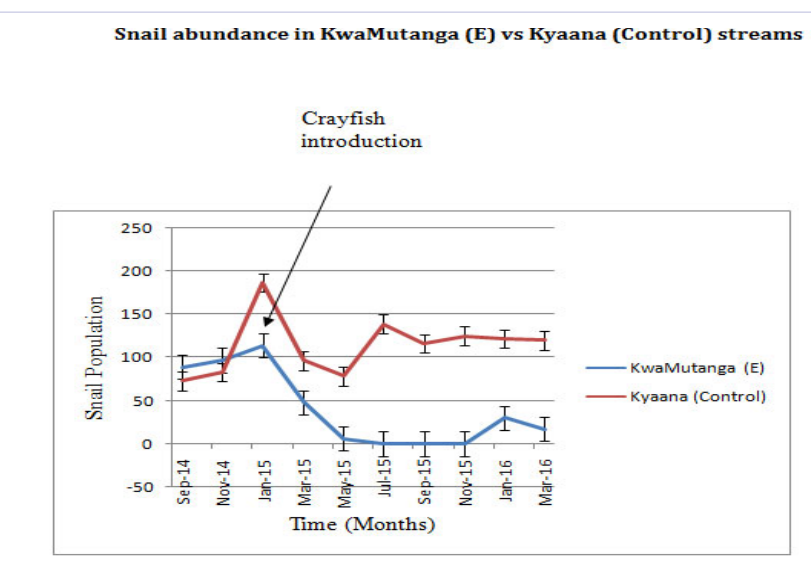

Figure 8: Snail population decline in KwaMutanga after crayfish introduction compared to Kyaana control stream 
Snail abundance in Kyanguli (E) vs Kamuongo (Control) streams

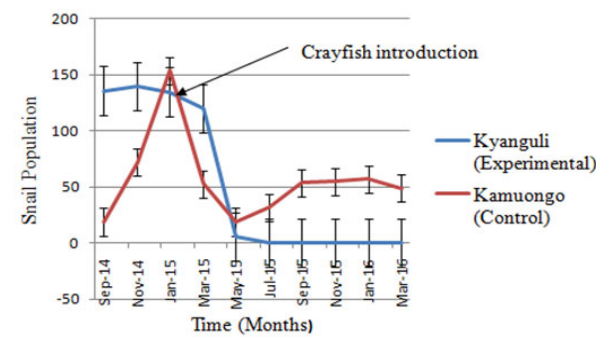

Figure 9: Snail population in Kyanguli after crayfish introduction compared to Kamuongo control stream

A comparison using one sample $t$ test shows significant difference $(t=4.651, p=0.001)$ of snail population between the two streams after crayfish was introduced in Kyanguli stream. Even though snail population was affected by environmental factors in Kamuongo stream, the same was also experienced in Kyanguli but the total decline was attributed to the predators (crayfish) introduction. The snail population in Kyanguli stream declined drastically from March 2015 and was totally eliminated by July 2015 through March 2016.

\begin{tabular}{|c|c|c|c|c|}
\hline $\begin{array}{c}\text { Experimental } \\
\text { Streams }\end{array}$ & $\begin{array}{c}\text { Snail } \\
\text { Abundance } \\
\text { Before } \\
\text { Crayfish } \\
\text { Introduction }\end{array}$ & $\begin{array}{c}\text { Snail } \\
\text { Abundance } \\
\text { After Crayfish } \\
\text { Introduction }\end{array}$ & $\begin{array}{c}\text { Statistical } \\
\text { Analysis } \\
\text { by Paired } \\
t \text {-Test }\end{array}$ & Pvalue \\
\hline Kyanguli & 411 & 0 & \multirow[b]{2}{*}{5.524} & \multirow[b]{2}{*}{0.0001} \\
\hline KwaMutanga & 300 & 17 & & \\
\hline \multicolumn{5}{|c|}{ Control Streams } \\
\hline Kyaana & 343 & 487 & \multirow[b]{2}{*}{7.727} & \multirow[b]{2}{*}{0.082} \\
\hline Kamuongo & 245 & 356 & & \\
\hline
\end{tabular}

\section{Discussion}

This study is the first attempt to determine the effect of crayfish on snail populations in stream habitats. Previous studies in small man-made ponds located within the Athi river Basin in Kenya showed that crayfish rapidly reduced snail numbers in such habitats, and indeed, in one stable habitat, they established self-sustaining populations and prevented re-establishment of snails for several months [25]. In the present study the effect of crayfish on pulmonate snail populations was determined in stream habitats. While crayfish are known to occur in stream habitats in Kenya, their ability to eliminate pulmonate snails of medical and veterinary significance in the country has not been determined. The fact that crayfish were able to persist at Kyanguli over several months and eliminated the snail populations in this habitat suggest that $P$. clarkii could play a role in control of snails of medical or veterinary significance in endemic areas such as Kenya. Although KwaMutanga stream seemed an ideal habitat for crayfish establishment, we experienced difficulties getting the crayfish to survive or establish in this habitat. While we do not have an explanation why crayfish could not establish in this habitat, we suspect pollutants that could potential kill the crayfish may have present in the stream. Apparently, the site at which we released the crayfish into the habitat is frequently used as a motorcycle taxis (locally popularly known bodaboda) washing site, and it is possible that petroleum products from the motor cycles such as oil or petrol may be responsible for failure of crayfish to survive and establish at this site.

Bio-control means for control of snails of medical or veterinary importance is preferred to chemical mollusciding, as it is not only considered environment friendly but also offers sustainability [25]. As schistosomiasis is transmitted from water sources frequent use of chemical molluscicides may have longterm adverse affects on water ecosystem as well as negatively affect people and animals that use the same water sources. In the search, for effective biological control agents against schistosometransmitting snails, the crayfish appears to be particularly promising given that it is an efficient predator of pulmonate snails responsible for transmitting disease causing parasites in both humans and livestock [26]. However, it is envisaged that the widespread use of this crustacean for snail control will most likely be based on continual or repeated restocking of the predator in the transmission sites analogous to the use of molluscicides as transmission sites of such parasites include seasonal streams which are subject to frequent flooding during heavy rains, which end up washing away the crayfish, or to drying out completely in the dry season which may lead to the disappearance of the crayfish [27].

In the current study, though adult crayfish were recovered in Kyanguli stream on subsequent bi-monthly sampling, it was not possible to tell whether the catches represented the originally introduced crayfish or their progenies, future studies should seek to uniquely tag the released crayfish to differentiate them from F1 and subsequent generations. The researchers recommend further work to establish the feasibility of the use of crayfish as biocontrol of schistosomiasis.

Although this study was limited by the number of study habitats, study duration, and also, experienced setbacks with flooding and in one habitat, possible human-related interference which, overall may have influenced the outcome of this study, the data obtained demonstrates the potential of the decapod crustacean, Procambarus clarkii, as a biological control agents against aquatic snails responsible for transmission of trematode parasites that cause disease in humans and domestic livestock, such as schistosomiasis (bilharzias) and fascioliasis (liver fluke disease) in stream habitats which may sometimes experience flooding or long dry season, and therefore, may require restocking or re-introductions, once in a while. Further studies on this crustacean should therefore, be encouraged. The study limitation included environmental factors such as floods, drought and human activity affected survival of the snails and thus 
limits generalization of the results. The snail survival in both experimental and control streams were negatively affected by flooding and human activity such as washing of motorbikes which would reduce the impact of the intervention strategy applied in this study. However, there is a clear indication that crayfish had significant impact to the decrease of the snail population in the experimental streams. This environmental impact would be reduced by replicating the study in artificial setting such as a swimming pool where most variables can be controlled.

\section{Conflict Of Interest}

Authors declared no conflict of interest

\section{Acknowledgements}

This research was funded through an Internal Research Grant (IRG) from the Kenya Medical Research Institute (KEMRI) referenced (PJ-611). We thank the communities that live near the study sites for their support and cooperation. We appreciate Messrs. Stephen Kamau and Newton Mwathi who supported field data collection. This paper is published with the approval of the Director, Kenya Medical Research Institute (KEMRI).

\section{References}

1. World Health Organization.http://www.who.int/mediacentre/ factsheets/fs115/en/2014.

2. Inobaya MT, Olveda RM, Chau TN, Olveda DU, Ross AG. Prevention and control of schistosomiasis: a current perspective. Res Rep Trop Med. 2014;5:65-75

3. Pica-Mattoccia L, Cioli D. Sex- and stage-related sensitivity of Schistosoma mansoni to in vivo and in vitro praziquantel treatment. Int J Parasitol. 2004;34(4):527-533.

4. Aragon AD, Imani RA, Blackburn VR, Cupit PM, Melman SD, Goronga T, et al. Towards an understanding of the mechanism of action of praziquantel. Mol Biochem Parasitol. 2009;164(1):57-65.

5. Fallon PG, Doenhoff MJ. Drug-resistant schistosomiasis: resistance to praziquantel and oxamniquine induced in Schistosoma mansoni in mice is drug specific. Am J Trop Med Hyg. 1994;51(1):83-88.

6. Steinauer ML, Melman SD, Cunningham C, Kubatko LS, Mwangi IN, Wynn NB. Reduced susceptibility to praziquantel among naturally occurring Kenyan Isolates of Schistosoma mansoni. PLOS Negl Trop Dis. 2009;3(8):e504. doi:10.1371/journal.pntd.0000504

7. Hala E, Marcel T, Robert N, Bergquist RN, Soraya S, Rashid B. Prophylactic effect of artemether on human Schistosomiasis mansoni among Egyptian Children: A randomized controlled trial. Acta Tropica. 2016;158:52-58.

8. Utzinger J, Chollet J, Jiqing Y, Jinyan M, Tanner M, Shuhua X. Effect of combined treatment with praziquantel and artemether on Schistosoma japonicum and Schistosoma mansoni in experimentally infected animals. Acta Tropica. 2001;80(1):9-18.

9. Spear RC, Seto E, Remais J, Carlton EJ, avis G, Qui D, et al. Fighting waterborne infectious diseases. Science. 2006;314(5802):10811083. doi:10.1126/science.314.5802.1081c
10. Fenwick A, Webster JP. Schistosomiasis: challenges for control, treatment and drug resistance. Curr Opin Infect Dis. 2006;19(6):577582.

11. Tchuem Tchuenté LA, Momo SC, Stothard JR, Rollinson D. Efficacy of praziquantel reinfection patterns in single and mixed infection foci for intestinal and urogenital schistosomiasis in Cameroon. Acta Tropica. 2013;128(2):275-283.

12. Secor WE. Water-based interventions for schistosomiasis control. Pathog Glob Health. 2014;108(5):246-254. doi:10.1179/20477732 14Y.0000000149

13. Webster BL, Diaw OT, Seye MM, Faye DS, Stothard JR, SousaFigueriredo JC, et al. Praziquantel treatment of school children from single and mixed infection foci of intestinal and urogenital schistosomiasis along the Senegal River Basin: Monitoring treatment success and re-infection patterns. Acta Trop. 2013;128(2):292-302. doi:10.1016/j.actatropica.2012.09.010

14. Lodge DM, Deines A, Gherardi F, Yeo DCJ, Arcella T, Baldridge AK, et al. Global introductions of Crayfishes: evaluating the impact of species invasions on ecosystem services. Annu Rev Ecol Evol Syst. 2012;43:449-472.

15. Prentice MA. Displacement of Biomphalaria glabrata by the snail Thiara granifera in field habitats in St. Lucia, West Indies. Ann Trop Med Parasitol.1983;77(1):51-59.

16. Pointier JP. Invading freshwater gastropods: some conflicting aspects for Public health. Malacologia. 1999;41(2):403-411.

17. Pointier JP. Comparison between two biological control trials of Biomphalaria glabrata in a pond in Guadeloupe, French West Indies. J Med Appl Mal. 1989;1:83-95.

18. Pointier JP, Guyard A. Biological control of the snail intermediate hosts of Schistosoma mansoni in Martinique, French West Indies. Trop Med Parasitol. 1992;43(2):98-101.

19. Duval D, Galinier R, Mouahid G, Toulza E, Allienne JF, Portela J, et al. A novel bacterial Pathogen of Biomphalaria glabrata: A potential weapon for Schistosomiasis Control? Plos Negl Trop Dis. 2015;9(2):e0003489. doi:10.1371/journal.pntd.0003489

20. Sokolow SH, Lafferty KD, Kuris AM. Regulation of laboratory populations of Snails (Biomphalaria and Bulinus spp.)by river prawns, Macrobrachium spp. (Decapoda, palaemonidae): Implications for control of schistosomiasis. Acta Trop. 2014;132:6474. doi:10.1016/j.actatropica.2013.12.013

21. Huner JV. Freshwater Crayfish: Biology, Management and Exploitation. Edited by Holdich DM, Lowery RS. Portland: Timber Press; Procambarus in North America and elsewhere 1988;239261.

22. Loker ES, Hofkin BV, Mkoji GM, Kihara JH, Mungai B, Koech DK. Procambarus clarkia in Kenya: does it have a role to play in the control of schistosomiasis? Aquaculture and Schistosomiasis: Proceedings of a Network Meeting Held in Manila, Philippines, August 6-10, 1991. 1992; Washington, DC: National Academy Press, 272-282. 
23. Lodge DM, Stein RA, Brown KM, Covich AP, Brönmark C, Garvey JE, et al. Predicting impact of freshwater exotic species on native biodiversity: challenges in spatial scaling. Australian Journal of Ecology. 1998;23(1):53-67.

24. Yue GH, Li JL, Wang CM, Xia JH, Wang GL, Feng JB. High prevalence of multiple paternity in the invasive crayfish species, Procambarus clarkii. Int J Biol Sci. 2010;6(1):107-115.

25. Mkoji GM, Hofkin BV, Kuris AM, Stewart-Oaten A, Mungai BN, Kihara JH, et al. Impact of the crayfish, Procambarus clarkia on Schistosoma haematobium transmission in Kenya. Am J Trop Med Hyg. 1999;61(5):751-759.
26. Sulieman Y, Pengsakul T, Guo Y, Huang SQ, Peng WX. Laboratory and Semi-Field Evaluation on the Biological Control of Oncomelania hupensis Snail (Gastropoda: Pomatiopsidiae), the intermediate host of Schistosoma japonicum, Using Procambarus clarkii crayfish (Crustacea: Cambaridae). Egyptian Journal of Biological Pest Control. 2013;23(1):215-220.

27. Sharma A, Diwevidi VD, Sigh S, Pawar KK, Jerman M, Singh LB, et al. Biological Control and its Important in Agriculture. International Journal of Biotechnology and Bioengineering Research. 2013;4(3):175-180. 